\title{
A Climatology of Disdrometer Measurements of Rainfall in Finland over Five Years with Implications for Global Radar Observations
}

\section{Leinonen, Jussi}

2012

Leinonen, J , Moisseev , D , Leskinen , M \& Petersen , W A 2012 , ' A Climatology of Disdrometer Measurements of Rainfall in Finland over Five Years with Implications for Global Radar Observations ', Journal of Applied Meteorology and Climatology , vol. 51 , no. 2 , pp. 392-404 . https://doi.org/10.1175/JAMC-D-11-056.1

http://hdl.handle.net/10138/36973

https://doi.org/10.1175/JAMC-D-11-056.1

publishedVersion

Downloaded from Helda, University of Helsinki institutional repository.

This is an electronic reprint of the original article.

This reprint may differ from the original in pagination and typographic detail.

Please cite the original version. 


\title{
A Climatology of Disdrometer Measurements of Rainfall in Finland over Five Years with Implications for Global Radar Observations
}

\author{
JUSSI LEINONEN \\ Finnish Meteorological Institute, Helsinki, and Department of Applied Physics, Aalto University, Espoo, Finland \\ DMITRI MOISSEEV AND MATTI LESKINEN \\ Department of Physics, University of Helsinki, Helsinki, Finland \\ WAlter A. Petersen* \\ NASA Marshall Space Flight Center, Huntsville, Alabama
}

(Manuscript received 16 March 2011, in final form 29 August 2011)

\begin{abstract}
To improve the understanding of high-latitude rain microphysics and its implications for the remote sensing of rainfall by ground-based and spaceborne radars, raindrop size measurements have been analyzed that were collected over five years with a Joss-Waldvogel disdrometer located in Järvenpää, Finland. The analysis shows that the regional climate is characterized by light rain and small drop size with narrow size distributions and that the mutual relations of drop size distribution parameters differ from those reported at lower latitudes. Radar parameters computed from the distributions demonstrate that the high latitudes are a challenging target for weather radar observations, particularly those employing polarimetric and dual-frequency techniques. Nevertheless, the findings imply that polarimetric ground radars can produce reliable "ground truth" estimates for space observations and identify dual-frequency radars utilizing a W-band channel as promising tools for observing rainfall in the high-latitude climate.
\end{abstract}

\section{Introduction}

The most important remotely retrieved rainfall-related variable for meteorological and hydrological purposes is generally agreed to be the total accumulated precipitation over a given period of time. The diameter $D$ of raindrops is of comparatively minor importance for the societal impact of rainfall; it does, however, have a major impact on the resultant estimates of precipitation parameters using radar remote sensing: whereas the volume of a raindrop is proportional to $D^{3}$, the backscatter signal for small drops depends on $D^{6}$. Consequently, the ability to

* Current affiliation: NASA Goddard Space Flight Center/Wallops Flight Facility, Wallops Island, Virginia.

Corresponding author address: Jussi Leinonen, Earth Observation, Finnish Meteorological Institute, P.O. Box 503, FIN-00101, Helsinki, Finland.

E-mail: jussi.leinonen@fmi.fi measure rain from a distance depends on the knowledge of the raindrop size and the variation thereof.

Dual-polarization radars are able to resolve the variability in the drop diameter by including a measurement that is sensitive to the size and shape of raindrops but not to the number of raindrops: the differential reflectivity (Bringi and Chandrasekar 2001). The specific differential phase measured by these radars can also be used to improve rain-rate retrievals, especially in the presence of heavy rain. The recent and upcoming rapid expansion in the operational deployment of polarimetric radars has the potential to alleviate the drop size problem in groundbased radars. Even before considering measurement noise, the retrievals are still not unambiguous, however, because the shape of the drop size distribution (DSD) also affects the radar returns. In addition, polarimetric technology for drop size inference is not currently available for space-based radar. To estimate the DSD with spaceborne radars such as the Dual-Frequency Precipitation Radar of the Global Precipitation Measurement (GPM) Core satellite, dual-frequency retrievals are used instead (Hou et al. 
2008). This approach is similar to the dual-polarization approach (Meneghini and Liao 2007) and also suffers from a problem of underdetermined measurements.

With the uncertainty in the retrievals, empirical formulas are typically used to relate the measured radar parameters to rain rate and the DSD parameters. Among widely known relations, the oldest is the reflectivity-rain-rate relation by Marshall et al. (1947). Since the introduction of the concept of polarimetric rain estimation (Seliga and Bringi 1976, 1978), many approaches that make use of polarimetric variables have been proposed and implemented over the recent decades (e.g., Sachidananda and Zrnic 1986; Gorgucci et al. 2002; Brandes et al. 2004). The usual weakness of such methods is that they are still formulated semiempirically on the basis of a limited set of rain measurements that is representative of the climate of the measurement location and, plausibly, other regions with similar geographical characteristics. Because the DSD measurements are most commonly made around centers of atmospheric science, the applicability of these retrieval algorithms to more remote locations is uncertain. In particular, DSD data from precipitation at the high midlatitudes and the lower Arctic latitudes (roughly $55^{\circ}-70^{\circ} \mathrm{N}$ ), which will be mostly covered by GPM (with the $65^{\circ}$ inclination of the Core satellite), have so far been limited. Relative to that of lower latitudes, such rain is characterized by lower average rain rates despite high rain occurrence in some areas (Kidd and Joe 2007).

To improve the understanding of drop size distributions in the above-mentioned region, we have analyzed data measured over parts of five years with a raindrop disdrometer located at Järvenpää in southern Finland. In this paper, we describe the analysis that was performed on this dataset and present a climatological description of the important DSD and radar parameters and their relationships.

\section{Measurements and data processing}

\section{a. Measurement setup}

To characterize the regional DSD and provide support for radar measurement analysis, a Joss-Waldvogel RD-69 impact disdrometer (JWD; Joss and Waldvogel 1967) was operated by the University of Helsinki in Järvenpää at $60^{\circ} 20^{\prime} 4^{\prime \prime} \mathrm{N}, 25^{\circ} 5^{\prime} 55^{\prime \prime} \mathrm{E}$ at an altitude of $56 \mathrm{~m}$ above mean sea level and roughly $30 \mathrm{~km}$ from the coast of the Gulf of Finland. The measurements have been made during the rainfall-dominated months of each year in the 2006-10 period (see Table 1 for the exact dates), with the disdrometer removed from its location during other parts of the year during which freezing temperatures and snowfall (which the JWD is unable to measure) are common in the area. The disdrometer gives the DSD by measuring drop size electromechanically from
TABLE 1. Measurement periods of the JWD during each year in the dataset.

\begin{tabular}{ccc}
\hline \hline Year & Start date & End date \\
\hline 2006 & 4 Jun & 2 Nov \\
2007 & 27 Apr & 31 Oct \\
2008 & 12 Jun & 11 Sep \\
2009 & 10 Jun & 5 Oct \\
2010 & 24 May & 31 Oct \\
\hline
\end{tabular}

the impact of drops on the top plate. In processing, the drop size is divided into 20 size bins, calibrated to cover the equivalent volume diameter (i.e., the diameter of the equivoluminal sphere) range of $0.32-5.62 \mathrm{~mm}$.

In total, the 2006-10 dataset used in this study contained approximately 390000 sixty-second integrated drop count spectra with at least one measured drop. After filtering out measurements that were nearly empty or were considered to be invalid (see section 2e for details), 71000 spectra remained.

\section{b. Validation}

For the purpose of verifying the reliability of the measurements, the JWD sensor stability was checked annually with standard-sized water drops in the laboratory, and a more thorough investigation was done in 2009 in which an optical size measurement made using the Hydrometeor Shape Detector (Barthazy et al. 2004) was compared with the JWD results.

As a further operational test, drop size data from September and October of 2010 were compared with those from a 2D video disdrometer (2DVD), which was temporarily located at the site at a point that was $\sim 30 \mathrm{~m}$ from the JWD, as a part of the Light Precipitation Validation Experiment organized by the National Aeronautics and Space Administration (NASA) CloudSat team with the support of the NASA GPM Ground Validation Program. The spectra from 20 October 2010 (UTC), one of the rainiest days of the experiment, are shown in Fig. 1. To achieve a fair comparison, the drop diameters from the 2DVD were sorted into bins that are identical to those used by the JWD.

Overall, the differences in the measured drop size spectra were of the same order as those reported by Sheppard and Joe (1994) and Tokay et al. (2005) when it could be verified that only liquid rain was falling. For the smallest drops, the JWD gives noticeably larger drop counts than the 2DVD; this behavior has been found to be normal in a low-noise environment (Tokay et al. 2003, 2005). Although this is likely due to the JWD being the more sensitive instrument at the small-drop end of the spectrum (the result of section 3a supports this assumption), the deviation implies some experimental uncertainty. The effect of such uncertainty depends on the application, but small drops normally 


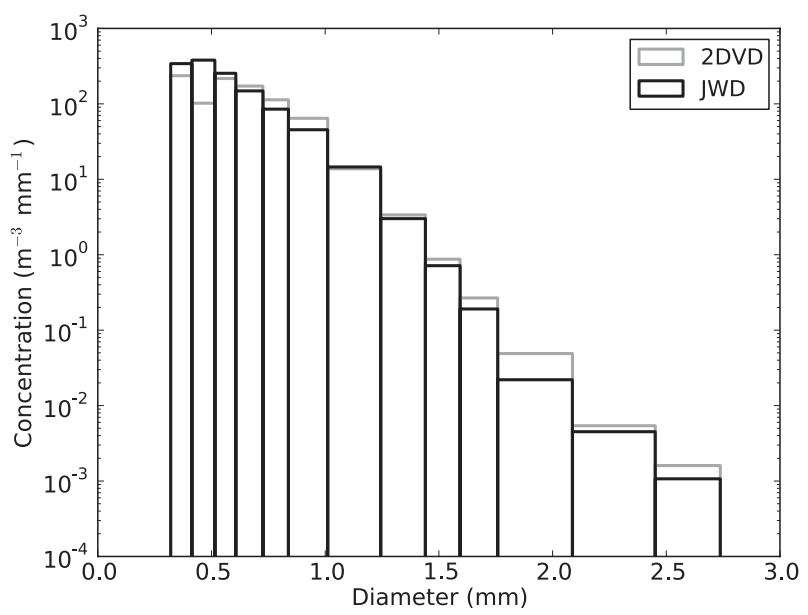

FIG. 1. Drop size spectra measured with the JWD (black outlines) and 2DVD (gray outlines) on 20 Oct 2010. The total integration time is $14.7 \mathrm{~h}$.

contribute only slightly to the precipitation and scattering parameters, which are dependent on higher powers of $D$. A notable exception may be drizzle, which is, however, ruled out by the filtering criteria of section $2 \mathrm{e}$. On a few days during the experiment, the temperature fell close to $0^{\circ} \mathrm{C}$ and wet snow was observed. In such cases, the 2DVD measured, as expected, many more large particles, but there was no indication of significant numbers of spurious raindrop detections by the JWD. Further validation will be enabled by later analysis of data from the other disdrometers at the site and the King Air aircraft that flew along spiral tracks over the site several times during the experiment.

\section{c. DSD estimation}

To derive the drop size distribution from the measured drop counts, the drop size bins were first converted into a continuous distribution $N_{m}(D)$ of drop counts by Gaussian histogram smoothing. The estimates of the DSD and radar parameters were not found to be very sensitive to the smoothing parameters. From $N_{m}(D)$, the DSD $N(D)$ can be computed as

$$
N(D)=\frac{N_{m}(D)}{A v(D) T},
$$

where $A=50 \mathrm{~cm}^{2}$ is the disdrometer sampling area, $T$ is the integration time, and $v(D)$ is the size-dependent terminal fall velocity of the drops. For $v(D)$, the formula by Brandes et al. (2002) was adopted. In this way, a continuous DSD was obtained, which could be directly used for the calculation of physical and radar parameters without the assumption of the normalized gamma form

$$
N(D)=N_{w} f(\mu)\left(\frac{D}{D_{0}}\right)^{\mu} \exp \left[-(3.67+\mu) \frac{D}{D_{0}}\right],
$$

where

$$
f(\mu)=\frac{6}{3.67^{4}} \frac{(3.67+\mu)^{\mu+4}}{\Gamma(\mu+4)},
$$

or another parameterization. Because bimodality and other features deviating from the gamma assumption were occasionally present in the 60 -s distributions, using the measured DSD directly leads to more accurate estimates of the DSD and scattering parameters.

\section{d. Parameters}

Because independence from DSD parameterizations was sought by using the nonparametric measured DSD, the properties of drop size and radar scattering were also computed directly from physical definitions (Bringi and Chandrasekar 2001) wherever possible. The discretization of drop sizes into bins by the JWD introduces some error into the calculation of moments; because the JWD bin size is on the order of $0.2 \mathrm{~mm}$ in the range in which the bulk of the data is located, this error can be estimated from Marzuki et al. (2010) to be at most approximately $6 \%-7 \%$. In a large dataset such as this, such errors can be expected to effectively average out.

With the known DSD $N(D)$, the median volume diameter $D_{0}$ can be obtained from the definition

$$
\int_{0}^{D_{0}} D^{3} N(D) d D=\frac{1}{2} \int_{0}^{D_{\max }} D^{3} N(D) d D .
$$

The rain rate $R$ can be computed as

$$
R=\int_{0}^{D_{\max }} v(D) D^{3} N(D) d D
$$

(with the appropriate unit conversions), and the rainwater content $W$ is computed as

$$
W=\frac{\pi}{6} \rho_{w} \int_{0}^{D_{\max }} D^{3} N(D) d D .
$$

The normalized intercept parameter $N_{w}$ of the gamma distribution with the same $D_{0}$ and $W$ is

$$
N_{w}=\frac{3.67^{4}}{\pi \rho_{w} D_{0}^{4}} W .
$$

Also used in this paper are the mass-weighted mean diameter,

$$
D_{m}=\int_{0}^{D_{\max }} D^{4} N(D) d D / \int_{0}^{D_{\max }} D^{3} N(D) d D,
$$

and the standard deviation of $D_{m}$, 
TABLE 2. The variables, their notation, and their corresponding units as used in this article.

\begin{tabular}{|c|c|c|}
\hline Variable & Symbol & Unit \\
\hline Drop diam & $D$ & $\mathrm{~mm}$ \\
\hline Median vol diam & $D_{0}$ & $\mathrm{~mm}$ \\
\hline $\begin{array}{l}\text { Mass-weighted mean } \\
\text { diam }\end{array}$ & $D_{m}$ & $\mathrm{~mm}$ \\
\hline $\operatorname{DFR}\left(\mathrm{K}_{\mathrm{u}} / \mathrm{W}\right)$ & $d_{R}^{\mathrm{K}_{\mathrm{u}} \mathrm{W}}$ & $\mathrm{dB}$ \\
\hline $\begin{array}{l}\text { Specific differential } \\
\text { phase }\end{array}$ & $K_{\mathrm{dp}}$ & ${ }^{\circ} \mathrm{km}^{-1}$ \\
\hline DSD & $N(D)$ & $\mathrm{mm}^{-1} \mathrm{~m}^{-3}$ \\
\hline $\begin{array}{l}\text { Normalized intercept } \\
\text { parameter }\end{array}$ & $N_{w}$ & $\mathrm{~mm}^{-1} \mathrm{~m}^{-3}$ \\
\hline Rain rate & $R$ & $\mathrm{~mm} \mathrm{~h}^{-1}$ \\
\hline Rainwater content & $W$ & $\mathrm{~g} \mathrm{~m}^{-3}$ \\
\hline Differential reflectivity & $z_{\mathrm{dr}}$ & Unitless \\
\hline $\begin{array}{l}\text { Logarithmic differential } \\
\text { reflectivity }\end{array}$ & $Z_{\mathrm{dr}}$ & $\mathrm{dB}$ \\
\hline $\begin{array}{l}\text { Radar reflectivity at } \\
\text { horizontal polarization }\end{array}$ & $z_{h}$ & $\mathrm{~mm}^{6} \mathrm{~m}^{-3}$ \\
\hline $\begin{array}{l}\text { Logarithmic reflectivity at } \\
\text { horizontal polarization }\end{array}$ & $Z_{h}$ & $\mathrm{~dB} Z$ \\
\hline $\begin{array}{l}\text { Shape parameter of a } \\
\text { gamma DSD }\end{array}$ & $\mu$ & Unitless \\
\hline Std dev of $D_{m}$ & $\sigma_{m}$ & $\mathrm{~mm}$ \\
\hline
\end{tabular}

$\sigma_{m}=\left[\int_{0}^{D_{\max }}\left(D-D_{m}\right)^{2} D^{3} N(D) d D / \int_{0}^{D_{\max }} D^{3} N(D) d D\right]^{1 / 2}$.

The shape parameter $\mu$ of the gamma distribution can be derived from these as

$$
\mu=\left(\sigma_{m} / D_{m}\right)^{2}-4
$$

Other ways to estimate $\mu$ exist (Bringi and Chandrasekar 2001), but the above form was found to be the most stable.

For computing the radar scattering from the DSDs, raindrops were modeled as oblate spheroids with the size-dependent axis ratios of Thurai et al. (2007). The orientation of the drops was considered to be partially aligned, with the angle of the symmetry axis being normally distributed with a 0 mean and a standard deviation of $7^{\circ}$ [as found by (Bringi et al. 2008)]. The refractive indices of water from Ray (1972) were used, assuming a temperature of $10^{\circ} \mathrm{C}$. A T-matrix code (Mishchenko 2000) was used to compute the radar parameters of interest-namely, the reflectivity at horizontal polarization $Z_{h}$, differential reflectivity $Z_{\mathrm{dr}}$, specific differential phase $K_{\mathrm{dp}}$, specific attenuation $A_{h}$ (likewise at horizontal polarization), and the dual-frequency ratio (DFR) $d_{R}$, defined as the ratio of reflectivities at two frequencies. Because we are also concerned with space radars and their ground validation, it is natural to adopt the following radar frequency bands and geometries: scattering at the $\mathrm{C}$ band (defined here as $5.6 \mathrm{GHz}$ ), the ground radar band used in the region, is simulated by assuming the radar beam is at an elevation angle of $0^{\circ}$. At the $\mathrm{K}_{\mathrm{u}}$ band $(13.6 \mathrm{GHz})$, the $\mathrm{K}_{\mathrm{a}}$ band (35.6 GHz), and the $\mathrm{W}$ band $(94.0 \mathrm{GHz})$, used in space radars, the beam is at an elevation angle of $90^{\circ}$. The notation and the corresponding units used throughout this paper are summarized in Table 2.

\section{e. Data filtering}

For the estimated parameters to be valid, enough data need to be gathered to avoid statistical and quantization errors. We set a minimum limit of a total of 20 drops for a 60-s DSD to be accepted in the analysis. For the same reason, we also required that drops be present in at least four consecutive disdrometer bins. The low minimum drop count was chosen because of the prevalence of light rain in the region. Because very low rain rates often occur naturally, minimum size limits that are much stricter would introduce filtering artifacts into the statistics. The low total drop count does introduce some sampling errors into the moment estimates, but the deterioration is expected to be minor because in a large dataset the errors are effectively averaged out; therefore we decided to emphasize the completeness of the climatological sample over some statistical accuracy. For more detailed studies on the influence of sampling, see, for example, Joss and Waldvogel (1969), Chandrasekar and Bringi (1987), Smith and Kliche (2005), and Moisseev and Chandrasekar (2007).

Some of the observed distributions also contained features that suggested measurement artifacts in the disdrometer. First, one of the size bins in the disdrometer occasionally had a large number of reported drops, with few or no drops in the surrounding bins. Because of the narrow peaks that this behavior caused, it could be identified using a threshold value of $D_{m} / \sigma_{m}>7.15$, determined empirically from a scatterplot of $D_{m}$ and $\sigma_{m}$. These erratic distributions were removed from the dataset. Second, large drops were sometimes found in distributions that otherwise consisted of small ones. These are probably due to outliers, nonmeteorological signals, or electrical errors, and they caused artifacts in many of the statistical products. A method that proved very successful at eliminating these was to remove the largest measured drop in a 60-s distribution if it was the only drop in its bin and if neither of the surrounding bins contained drops. In contrast to the former error source, these distributions remained in the dataset after filtering and were not otherwise modified.

In addition, simulations of DSD truncation in gamma distributions showed that Eq. (4) overestimates $D_{0}$ at low values. The error decreases rapidly as the true $D_{0}$ increases, being less than $20 \%$ for $D_{0}>0.5 \mathrm{~mm}$ if $\mu=0$; 


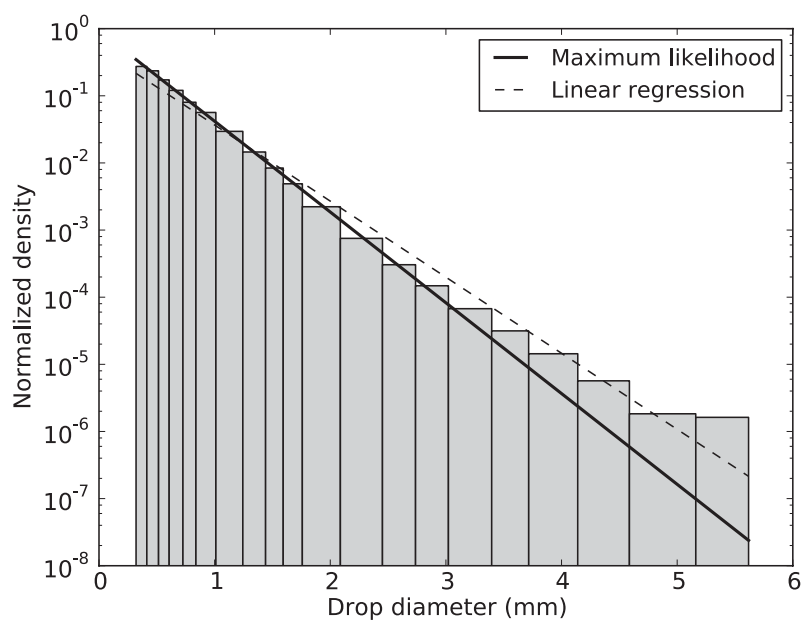

FIG. 2. The normalized DSD of the whole dataset.

for higher values of $\mu$, the decrease is even faster. Thus, only distributions for which $D_{0}>0.5 \mathrm{~mm}$ were considered to be acceptable for inclusion in the statistics; these were included without further modification.

\section{Results}

\section{a. Long-term drop size distribution}

From the total drop counts measured during the entire measurement period, we were able to derive a long-term probability distribution of the sizes of drops in a unit volume, nearly independent of the influence of individual rainfall events. This distribution, which is useful as prior information in retrievals, was found to be a good fit to the exponential distribution, given in normalized form as

$$
N(D)=\lambda \exp (-\lambda D)
$$

This form has been used for long-term distributions by many former studies [starting from Marshall and Palmer (1948)].

To ensure that all observations were properly included, we relaxed (for this long-term distribution only) the filtering limits that were described in section 2e. DSDs that were considered to originate from error sources (i.e., those failing the $D_{m} / \sigma_{m}$ test) were still deleted, and the erratic large drops were eliminated, but we removed the required minima for the number of drops, for the consecutive bins containing drops, and for $D_{0}$. The latter three criteria were only used to improve the reliability of parameter estimates from short-time-span measurements and thus were not needed in this context, because the long integration time negates these problems.

Figure 2 illustrates the long-term distribution as a histogram corresponding to the JWD size bins. We used the

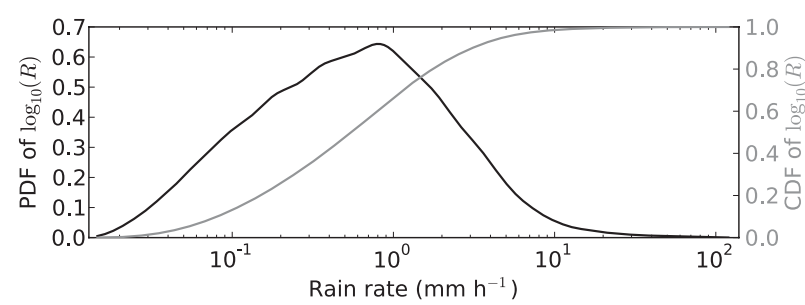

FIG. 3. The probability density function (PDF) and the cumulative distribution function (CDF) of the rain rate $R$.

maximum-likelihood approach to distribution estimation to fit the exponential form. This fit highlights the remarkable conformity of the measurements to the exponential model from the detection limit of $0.32 \mathrm{~mm}$ to roughly $3 \mathrm{~mm}$. We speculate that a fundamental stochastic reason, similar to that found for rain rate by Kedem and Chiu (1987), may be responsible for this asymptotic behavior. At larger diameters, the observations indicate higher drop concentrations than the model does, but because the total observed drop counts in this range are less than 20000 per bin (and as few as 334 in the largest size bin) for the whole 5 -yr period, it is plausible (although by no means is it certain) that this deviation is due to an insufficient number of observations rather than a physical cause.

The parameter obtained from the fit, $\lambda=3.11$, corresponds to the Marshall-Palmer distribution at $R=$ $3.6 \mathrm{~mm} \mathrm{~h}^{-1}$. Alternatively, a linear-regression fit on the logarithmic drop concentrations resulted in $\lambda=2.61$, giving a better match for the full range of diameters but a poor characterization of the linear slope of the abovementioned range.

\section{b. Distributions of parameters}

In Figs. 3-10, we present the probability distributions of various DSD and scattering parameters. These have been estimated from the samples using kernel density estimation [for an overview, see, e.g., Silverman (1986)]. The variables were chosen for further inspection on the basis of general importance in rainfall and radar studies (such as $R, D_{0}$, and $Z_{h}$ ) or of specific interest expressed in recent studies - for example, the dual-frequency retrieval algorithms for the next-generation spaceborne radars use $W, A_{h}$, and $d_{R}$ (Mardiana et al. 2004; Kuo et al. 2004).

The distributions of the rain rate, the median volume diameter, and the shape parameter again emphasize the prevalence of light, small-drop rainfall with narrow size spectra in the regional climate. The mean values were $\bar{R}=1.34 \mathrm{~mm} \mathrm{~h}^{-1}$ (Fig. 3), $\bar{D}_{0}=1.02 \mathrm{~mm}$ (Fig. 4), $\bar{N}_{w}=4900 \mathrm{~mm}^{-1} \mathrm{~m}^{-3}$ (Fig. 5), and $\bar{\mu}=8.8$ (Fig. 6), with values as high as $\mu=20-30$ occurring commonly. The estimate of $\mu$ is affected by the integration time: if it is increased to $180 \mathrm{~s}$, the mean $\mu$ decreases to 4.9. Even so, 


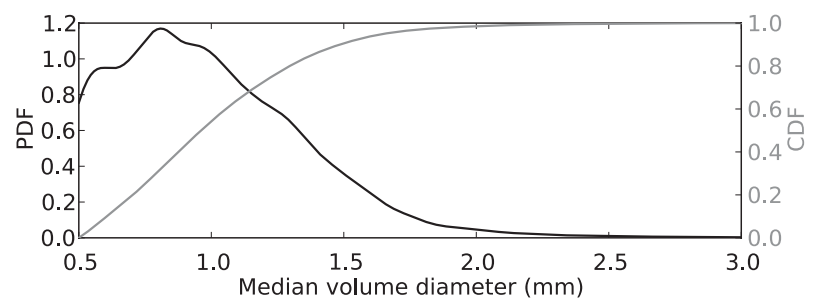

FIG. 4. As in Fig. 3, but for the median volume diameter $D_{0}$.

these values are larger (and the distributions correspondingly narrower) than those given by Bringi and Chandrasekar (2001). Given the simple relations of the rain rate to the water content, the distribution of $W$ (Fig. 7) is, unsurprisingly, similar to that of $R$. We note that because $\log _{10}(R)$ has a distribution that is close to normal it is in many contexts natural to consider the logarithm instead of the linear value of $R$.

The small drop size also has consequences for the radar reflectivity (Fig. 8) in that the distributions of reflectivity at different frequencies are similar (i.e., the deviation from the Rayleigh approximation is small) except for the W band, for which resonance scattering effects cause the near absence of values of $Z_{h}$ that are $>25 \mathrm{dBZ}$. The differences in $A_{h}$ (Fig. 9) and $d_{R}$ (Fig. 10) between frequencies are much more pronounced. As expected, C-band ground radars experience significant attenuation only over long distances. Spaceborne vertically pointing radars at higher frequencies have a higher specific attenuation, but their signal travels a shorter distance in the rain. With the typical variation of the melting-layer altitude between 1 and $3 \mathrm{~km}$, the typical two-way path-integrated attenuation of the ground echo that can be attributed to rain is roughly $0.1 \mathrm{~dB}$ for the $\mathrm{K}_{\mathrm{u}}$ band, $1 \mathrm{~dB}$ for the $\mathrm{K}_{\mathrm{a}}$ band, and $10 \mathrm{~dB}$ for the $\mathrm{W}$ band. In more-extreme cases, the attenuation can be more than an order of magnitude stronger for each band.

The main practical importance in the distributions of the radar parameters is in what they imply for the ability of radars to detect and quantify rainfall. For $Z_{h}$, we see that $\mathrm{C}$-band ground-based radars, which typically have detection thresholds below $0 \mathrm{dBZ}$, can detect practically all rainfall that is measured with the disdrometer and that passes through the filtering (we remind the reader that all distributions presented here are conditional to the filtering described in section 2e). A similar conclusion can be made about W-band satellite radars, which are also very sensitive [e.g., a lowest detectable signal of $-30 \mathrm{dBZ}$ for CloudSat (Stephens et al. 2008)]. For GPM and other planned $\mathrm{K}_{\mathrm{u}} / \mathrm{K}_{\mathrm{a}}$-band satellite radars, the detectability is less certain. The lowest detected reflectivity for GPM is from $12\left(\mathrm{~K}_{\mathrm{a}}\right)$ to $18\left(\mathrm{~K}_{\mathrm{u}}\right) \mathrm{dBZ}$ at full swath width (Satoh et al. 2004), indicating that approximately

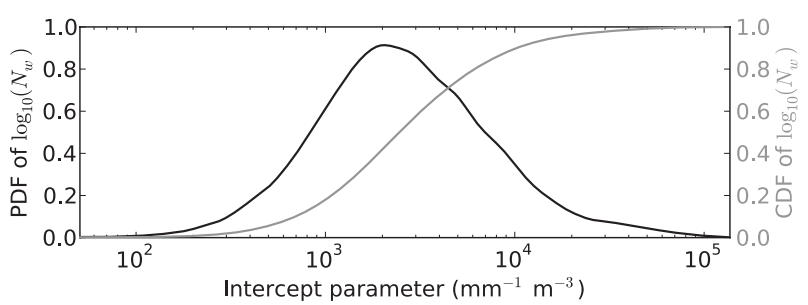

FIG. 5. As in Fig. 3, but for the normalized intercept parameter $N_{w}$.

$55 \%$ of the rainfall can be detected with the $\mathrm{K}_{\mathrm{u}}$-band radar at full swath width (the worst case). Using a narrower radar swath can improve the detection performance significantly at the cost of coverage. Because most of the data that were filtered out of the statistics by the constraint $D_{0}>0.5 \mathrm{~mm}$ are very light rain and are likely to be undetectable, the detection frequency for all rain is somewhat less than this. We note, though, that many of the cases with $D_{0}<0.5 \mathrm{~mm}$ are drizzle, which may not be appropriate to consider as being of the same class as normal rain because of the different physical processes involved.

For the DFR (Fig. 10) and the differential reflectivity (Fig. 11), a similar assessment can be made. The small drop sizes in the region pose a problem for both of these approaches, because small raindrops exhibit Rayleigh scattering and are also close to being spherical. For $Z_{\mathrm{dr}}$, a large difference in the performance of currently available dualpolarization radars can be predicted. The generally accepted lower limit for the detection of $Z_{\mathrm{dr}}$ is on the order of $0.2 \mathrm{~dB}$, corresponding to a detectability of $49 \%$ of the considered cases. Spatial averaging can reduce the lower limit, potentially increasing the detectability to, for example, $80 \%$ for a limit of $0.1 \mathrm{~dB}$. The DFR signals from the DSDs are above the detectable limit of $1-2 \mathrm{~dB}$ at the $\mathrm{K}_{\mathrm{u}} / \mathrm{W}$ and $\mathrm{K}_{\mathrm{a}} / \mathrm{W}$ combinations for at least $85 \%$ of time, although this figure does also include cases in which one of the two signals would be below the absolute detection threshold. The case with the $\mathrm{K}_{\mathrm{u}} / \mathrm{K}_{\mathrm{a}} \mathrm{DFR}$ is more complicated, with the DFR mostly less than $0 \mathrm{~dB}$; this is discussed further in the next section.

The usability of the specific differential phase $K_{\mathrm{dp}}$ (Fig. 12) is particularly limited in this climate because of the light rain and the high noise levels of $K_{\mathrm{dp}}, 0.3^{\circ} \mathrm{km}^{-1}$ (Bringi and Chandrasekar 2001) or lower, approximately

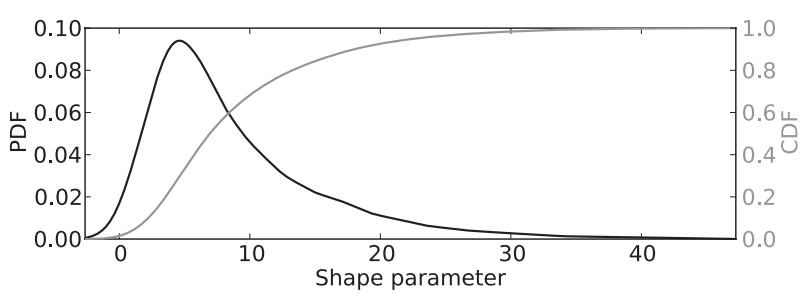

FIG. 6. As in Fig. 3, but for the shape parameter $\mu$. 


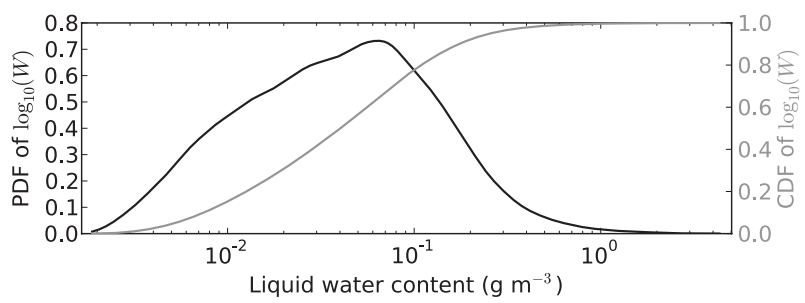

FIG. 7. As in Fig. 3, but for the liquid water content $W$.

$0.1^{\circ} \mathrm{km}^{-1}$, with spatial averaging. Even at a threshold of $0.1^{\circ} \mathrm{km}^{-1}$, only $7 \%$ of all rainfall can be detected. Nevertheless, $K_{\mathrm{dp}}$ can be used to improve results during the high-impact heavy-rain cases.

The qualitative implication of these findings for GPM ground validation is that the performance of the groundbased radar network can be expected to exceed that of the satellite in most cases, thus providing a tool to evaluate the satellite retrieval algorithms also at high latitudes [for a general overview of the subject, see Chandrasekar et al. (2008)]. Put more precisely, the ground-based observations are able to provide a reference measurement for all cases in which GPM is able to detect a signal, especially since the smaller radar bin size of the ground radars permits the use of spatial averaging. Furthermore, although polarimetric DSD parameter retrieval may be difficult for light rain with small drops, at those conditions raindrops tend to exhibit Rayleigh scattering at the GPM frequencies, allowing the reflectivity values of ground-based and space-based measurements to be compared directly.

We note that if they are measured by accumulation rather than by occurrence then the above detection rates will be much higher, because the rainfall events that contribute the largest amount of water are also those that generate the most-detectable radar signals.

\section{c. Relations of rain parameters}

\section{1) SCALED DROP SIZE DISTRIBUTIONS}

The form of Eq. (2) suggests that by scaling to the dimensionless quantities $D / D_{0}$ and $N(D) / N_{w}$, one can normalize all DSDs to similar forms. This has been shown

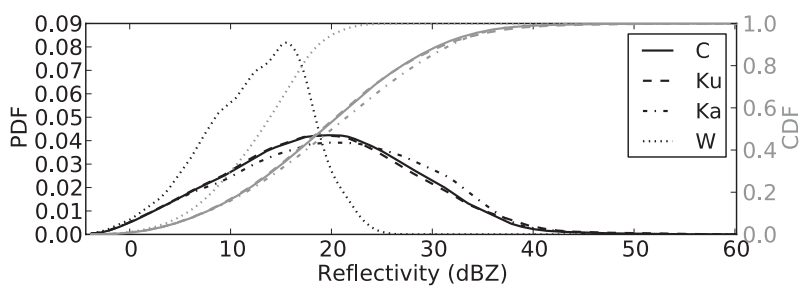

FIG. 8. As in Fig. 3, but for the horizontally polarized radar reflectivity $Z_{h}$ at various frequencies.

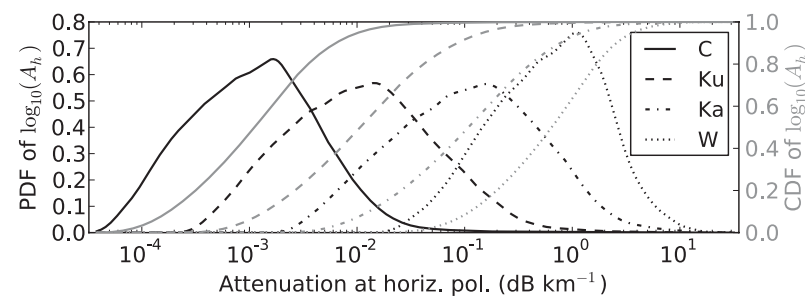

FIG. 9. As in Fig. 3, but for the horizontally polarized specific attenuation $A_{h}$ at various frequencies.

to be the case in experiments by, for example, Sekhon and Srivastava (1971) and Willis (1984) for exponential distributions and by Testud et al. (2001), Bringi et al. (2003), and Illingworth and Blackman (2002) for gamma distributions. In Fig. 13, we show this normalization applied to our dataset and compare the form of the DSDs with gamma distributions. The form of the scaled distributions is in good agreement with the direct estimates of $\mu$. In contrast to the long-term average, relatively few 60 -s distributions correspond well to the exponential form $(\mu=0)$.

\section{2) DROP SIZE IN CONVECTIVE AND STRATIFORM RAIN}

Bringi et al. (2003) investigated the distribution of the mass-weighted mean diameter $D_{m}$ and the intercept parameter $N_{w}$ in stratiform and convective rain. These were defined using $R$ and the standard deviation of $R$ over five consecutive samples, defined as $\sigma_{R}$. Stratiform rain corresponded to $R>0.5 \mathrm{~mm} \mathrm{~h}^{-1}$ and $\sigma_{R}<1.5 \mathrm{~mm} \mathrm{~h}^{-1}$, and convective rain corresponded to $R>5 \mathrm{~mm} \mathrm{~h}^{-1}$ and $\sigma_{R}>1.5 \mathrm{~mm} \mathrm{~h}^{-1}$ (Bringi et al. 2003, their Figs. 10, 11). In their disdrometer observations from diverse climates from different regions of the globe, the scatter of mean $D_{m}$ and $\log _{10}\left(N_{w}\right)$ in rain events fell almost on a straight line for stratiform rain, whereas the scatter for convective rain formed two clusters that corresponded roughly to maritime and continental climates.

Using these definitions of stratiform and convective, we present our corresponding results in Fig. 14. The scatter of our stratiform rain events is also close to linear, but the mean value is lower (i.e., gives smaller average values of

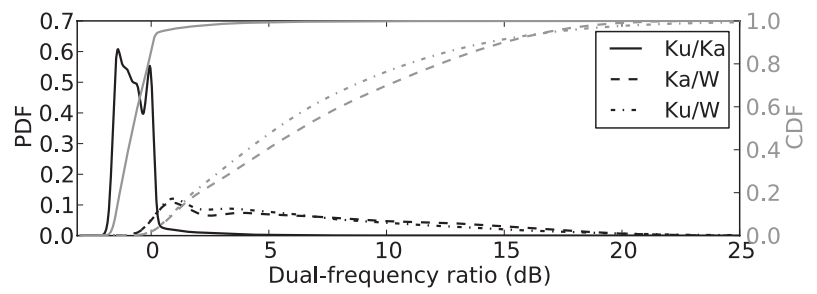

FIG. 10. As in Fig. 3, but for the DFR at various frequency combinations. 


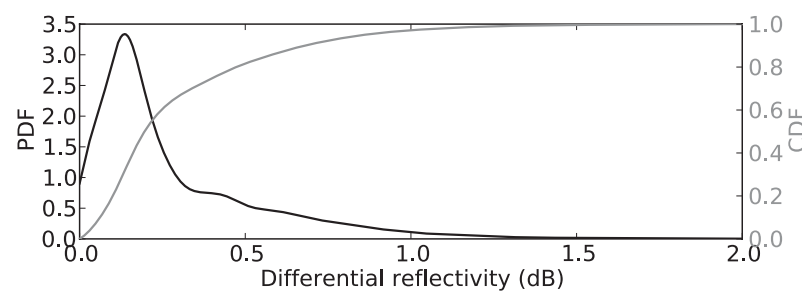

FIG. 11. As in Fig. 3, but for the differential reflectivity $Z_{\mathrm{dr}}$ at the $\mathrm{C}$ band.

$N_{w}$ for a given $D_{m}$ ) than that of their trend, except for drop sizes closer to $D_{m}=2 \mathrm{~mm}$. For convective rain, we do not observe a clustering of the data into either of the clusters given by their paper. The high- $D_{m}$ cases roughly match the continental cluster, but the majority of the data points are concentrated around $D_{m}=1.5 \mathrm{~mm}$ and $N_{w}=$ $5000 \mathrm{~mm}^{-1} \mathrm{~m}^{-3}$, suggesting a high-latitude cluster in this climate. Note that no data points match the maritime convective cluster, despite the proximity of the Baltic Sea.

\section{d. Radar-rainfall relations}

The radar parameters that were simulated from the DSDs suggest relations that connect these parameters to the physical properties of the DSD. Most fundamental, perhaps, is that the correspondence of the radar reflectivity and the rain rate - the " $Z-R$ relation" - can be derived for the regional climate. Such relations are the simplest approach to estimating rain rate with radars, but they are also inherently ambiguous and have plenty of variation around the mean. Nevertheless, with nonpolarimetric radars, they are typically the only available option for rain-rate retrieval. Empirical formulas are typically of the form

$$
z_{h}=a R^{b}
$$

where $z_{h}$ is in units of millimeters to the sixth power per cubic meter, $R$ is in millimeters per hour, and the constants $a$ and $b$ depend on the local climate.

There has been some discussion as to what kind of regression setup should be used to determine the coefficients, for example by Campos and Zawadzki (2000), who also noted that the type of disdrometer typically affects the resulting constants. Nonlinear regression puts weight on the large values, and the resulting relation failed by an order of magnitude for the low rain rates. At the $\mathrm{C}$ and $\mathrm{K}_{\mathrm{u}}$ bands, use of linear regression after taking the logarithm of Eq. (12), with $\log _{10} R$ as a function of $\log _{10} z_{h}$, produced a fit that not only described the whole distribution well but also avoided misestimation of the rain rate at the high-rain-rate end, which can be a potentially dangerous fault in operational use. This approach resulted in the coefficients given in Table 3. The coefficients for the $\mathrm{K}_{\mathrm{a}}$ and $\mathrm{W}$ bands are given as well, but

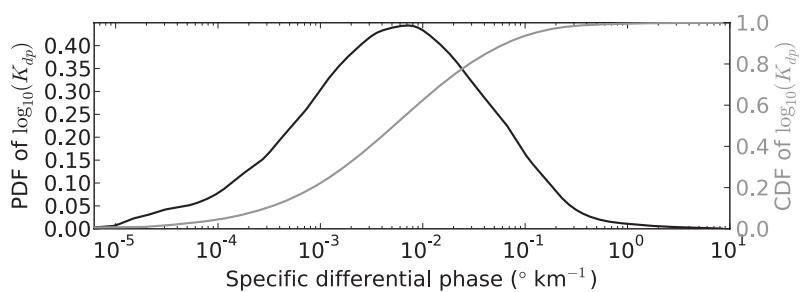

FIG. 12. As in Fig. 3, but for the specific differential phase $K_{\mathrm{dp}}$ at the $\mathrm{C}$ band.

the joint distribution of $\log _{10}(R)$ and $\log _{10}\left(z_{h}\right)$ was less linear for these, and the line fits may be unsatisfactory even though the error remains similar to that of the $\mathrm{C}$ band.

The scatter around the fitted line in the $Z-R$ relation can be reduced by using a normalized form with the quantities $z_{h} / N_{w}$ and $R / N_{w}$. At the $\mathrm{C}$ band, the relation between the logarithms of the normalized quantities is linear, but this property is lost at the frequencies at which Mie scattering is relevant - the $\mathrm{W}$ band in particular. Therefore, we adapted the form

$$
\log _{10}\left(R / N_{w}\right)=a_{R} \log _{10}\left(z_{h} / N_{w}\right)^{2}+b_{R} \log _{10}\left(z_{h} / N_{w}\right)+c_{R}
$$

for the normalized relation. Similarly, $D_{0}$ can be related to the normalized reflectivity with minimal scatter as

$$
\log _{10} D_{0}=a_{D} \log _{10}\left(z_{h} / N_{w}\right)^{2}+b_{D} \log _{10}\left(z_{h} / N_{w}\right)+c_{D} .
$$

The coefficients to the fitted relations can be found in Table 3, and they are illustrated in Fig. 15.

For polarimetric raindrop size determination, the relation of the median volume diameter $D_{0}$ to $Z_{\mathrm{dr}}(\mathrm{C}$ band $)$ is

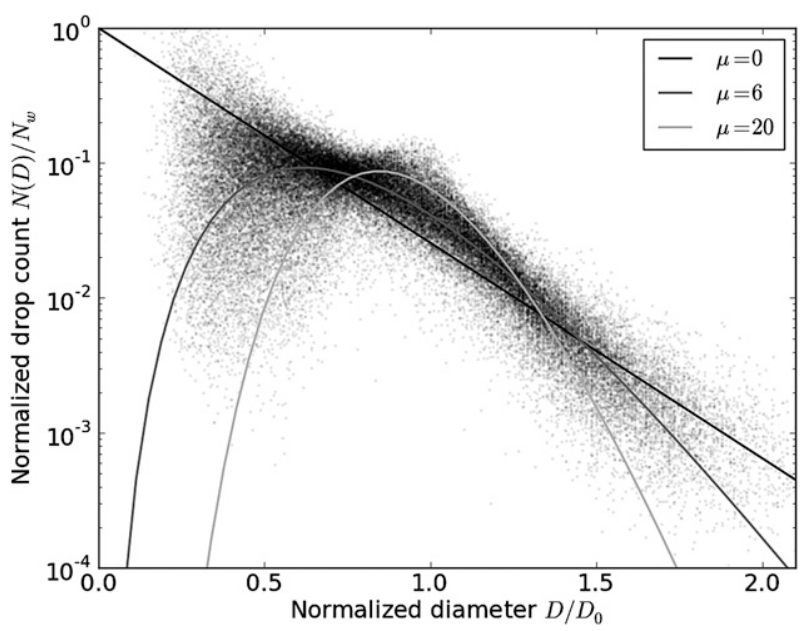

FIG. 13. The normalized DSDs of the full dataset in comparison with the gamma distribution at $\mu=0, \mu=6$, and $\mu=20$. 

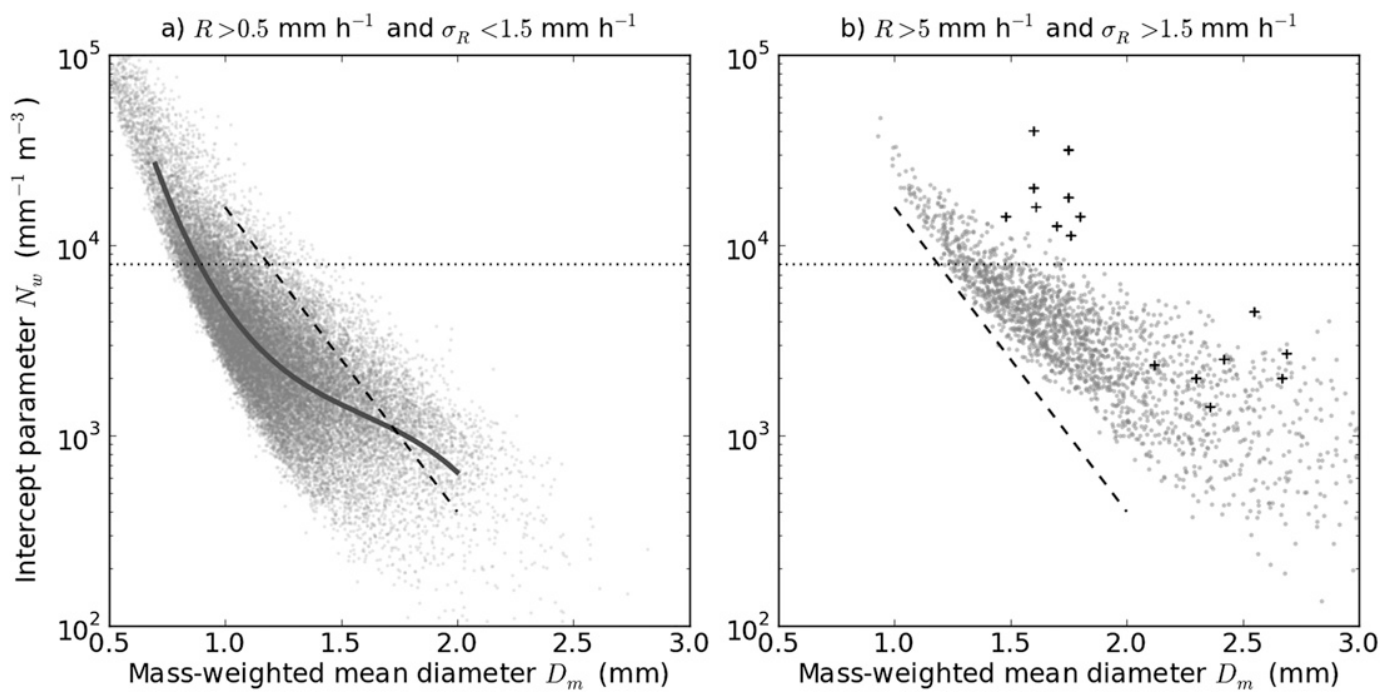

FIG. 14. Scatterplots of the intercept parameter and the mass-weighted mean diameter for (a) stratiform rain $[R>$ $0.5 \mathrm{~mm} \mathrm{~h}^{-1}$ and $\sigma_{R}<1.5 \mathrm{~mm} \mathrm{~h}^{-1}$; the solid line gives the mean, the dashed line is from Bringi et al. (2003, their Fig. 10 ), and the dotted line corresponds to the Marshall-Palmer distribution with $N_{w}=8000$ ] and (b) convective rain $\left[R>5 \mathrm{~mm} \mathrm{~h}^{-1}\right.$ and $\sigma_{R}>1.5 \mathrm{~mm} \mathrm{~h}^{-1}$; the black dots are from Bringi et al. (2003, their Fig. 11)].

illustrated in Fig. 16. As noted in the context of the distribution of $Z_{\mathrm{dr}}$, its noise level, and the resulting detection threshold, can have a large effect on the performance of drop sizing. It can be seen that the standard deviation of
$Z_{\mathrm{dr}}$ for a given $D_{0}$ that is due to DSD variability is approximately $0.1 \mathrm{~dB}$, which is somewhat less than the typical observation noise of $0.2 \mathrm{~dB}$. A piecewise fit gives a once-differentiable function,

$$
D_{0}=\left\{\begin{array}{ll}
-7.34 Z_{\mathrm{dr}}^{4}+17.9 Z_{\mathrm{dr}}^{3}-15.3 Z_{\mathrm{dr}}^{2}+6.20 Z_{\mathrm{dr}}+0.232, & 0.1<Z_{\mathrm{dr}} \leq 0.8 \mathrm{~dB} \\
1.79 Z_{\mathrm{dr}}^{0.569}, & 0.8 \mathrm{~dB}<Z_{\mathrm{dr}}
\end{array},\right.
$$

where a polynomial is used at the small-drop end to capture the details of the distribution and a power law, similar to that by Bringi et al. (2002), is used for the large drops to ensure reasonable behavior at high values of $Z_{\mathrm{dr}}$.

In vertically pointing airborne and spaceborne radars, the DFR can be used to constrain the drop size. In operational use, the DSD parameters are usually retrieved from an algorithm that combines the measured data together instead of using an explicit DFR- $D_{0}$ relationship (see, e.g., Meneghini et al. 1992). Nevertheless, examining the sensitivity of DFR to $D_{0}$ can help to determine the usefulness of dual-frequency observations in constraining the DSD parameters. From Fig. 17, it is evident that the selection of the frequency pair has a large effect on $D_{0}$ retrieval performance. The small and mostly negative (on the decibel scale) values of the $\mathrm{K}_{\mathrm{u}} / \mathrm{K}_{\mathrm{a}}$ DFR indicate that raindrop sizing with these frequencies cannot generally be done in a straightforward way and that extracting useful information from the DFR requires advanced techniques (e.g., inverse methods in satellite data interpretation) that are not considered in this study. This anomalous behavior, noted before by Matrosov et al. (2005), arises from a coincidental positive scattering resonance at the $\mathrm{K}_{\mathrm{a}}$ band at roughly $0.9<D<2.4 \mathrm{~mm}$, which forces the $\mathrm{K}_{\mathrm{a}}$-band reflectivity to be slightly higher than that at the $\mathrm{K}_{\mathrm{u}}$ band. The relation of $D_{0}$ to the $\mathrm{K}_{\mathrm{a}} / \mathrm{W}$ and $\mathrm{K}_{\mathrm{u}} / \mathrm{W}$ DFRs is generally monotonic, although still somewhat scattered, and should allow the $D_{0}$ to be constrained better, especially for light rain for which the attenuation at $\mathrm{W}$ band is less significant. For these data, the shape of the relation is too complex for a power law, and we derived the empirical polynomial functions

$$
\begin{aligned}
D_{0}= & 4.03 \times 10^{-4}\left(d_{R}^{\mathrm{K}_{\mathrm{a}} \mathrm{W}}\right)^{3}-1.03 \times 10^{-2}\left(d_{R}^{\mathrm{K}_{\mathrm{a}} \mathrm{W}}\right)^{2} \\
& +1.34 \times 10^{-1} d_{R}^{\mathrm{K}_{\mathrm{a}} \mathrm{W}}+4.23 \times 10^{-1} \text { and } \\
D_{0}= & 1.03 \times 10^{-4}\left(d_{R}^{\mathrm{K}_{\mathrm{u}} \mathrm{W}}\right)^{3}-3.42 \times 10^{-3}\left(d_{R}^{\mathrm{K}_{\mathrm{u}} \mathrm{W}}\right)^{2} \\
& +9.32 \times 10^{-2} d_{R}^{\mathrm{K}_{\mathrm{u}} \mathrm{W}}+5.43 \times 10^{-1}
\end{aligned}
$$

for $3<d_{R}^{\mathrm{K}_{\mathrm{a}} \mathrm{W}}<20 \mathrm{~dB}$ and $3<d_{R}^{\mathrm{K}_{\mathrm{u}} \mathrm{W}}<25 \mathrm{~dB}$, respectively. 
TABLE 3. The coefficients of Eqs. (12), (13), and (14) at different frequency bands. The coefficients $a_{R}, b_{R}$, and $c_{R}$ are valid for $10^{-5}<R / N_{w}<5 \times 10^{-2} \mathrm{~mm}^{2} \mathrm{~m}^{3} \mathrm{~h}^{-1}$, and the coefficients $a_{D}, b_{D}$, and $c_{D}$ are valid for $0.5<D_{0}<3.0 \mathrm{~mm}$.

\begin{tabular}{ccccc}
\hline \hline Band & $a$ & $b$ & & $\begin{array}{c}\text { Relative RMSE } \\
\text { for } R\end{array}$ \\
\hline $\mathrm{C}$ & 223 & 1.53 & & $32.7 \%$ \\
$\mathrm{~K}_{\mathrm{u}}$ & 233 & 1.59 & & $36.8 \%$ \\
$\mathrm{~K}_{\mathrm{a}}$ & 267 & 1.58 & & $34.6 \%$ \\
$\mathrm{~W}$ & 32 & 0.89 & & $39.3 \%$ \\
& & & & Relative RMSE \\
Band & $a_{R}$ & $b_{R}$ & $c_{R}$ & for $R / N_{w}$ \\
\hline $\mathrm{C}$ & -0.0330 & 0.668 & -2.68 & $14.0 \%$ \\
$\mathrm{~K}_{\mathrm{u}}$ & -0.0176 & 0.611 & -2.72 & $15.9 \%$ \\
$\mathrm{~K}_{\mathrm{a}}$ & 0.0180 & 0.711 & -2.74 & $15.7 \%$ \\
$\mathrm{~W}$ & 0.372 & 2.93 & 0.77 & $20.8 \%$ \\
& & & & Relative RMSE \\
Band & $a_{D}$ & $b_{D}$ & $c_{D}$ & for $D_{0}$ \\
\hline $\mathrm{C}$ & 0.00616 & 0.144 & 0.196 & $3.12 \%$ \\
$\mathrm{~K}_{\mathrm{u}}$ & -0.00256 & 0.131 & 0.187 & $3.44 \%$ \\
$\mathrm{~K}_{\mathrm{a}}$ & 0.00501 & 0.152 & 0.184 & $3.43 \%$ \\
$\mathrm{~W}$ & 0.0829 & 0.637 & 0.944 & $3.96 \%$ \\
\hline
\end{tabular}

Algorithms for C-band polarimetric rain-rate retrieval of the type presented in Bringi and Chandrasekar (2001) were also estimated for the data. For $R\left(z_{h}, z_{\mathrm{dr}}\right)$, we have

$$
R=0.0122 z_{h}^{0.820} z_{\mathrm{dr}}^{-2.28},
$$

conditional to $Z_{\mathrm{dr}}>0.1 \mathrm{~dB}$, with a root-mean-square (RMS) relative error of $25.4 \%$. For $R\left(K_{\mathrm{dp}}\right)$, we get

$$
R=21.0 K_{\mathrm{dp}}^{0.720}
$$

with an RMS error of $27.5 \%$, and for $R\left(K_{\mathrm{dp}}, z_{\mathrm{dr}}\right)$,

$$
R=29.7 K_{\mathrm{dp}}^{0.890} z_{\mathrm{dr}}^{-0.927}
$$

with an RMS error of $13.9 \%$. The latter two are conditional to $K_{\mathrm{dp}}>0.4^{\circ} \mathrm{km}^{-1}$, corresponding to $R \gtrsim 5 \mathrm{~mm} \mathrm{~h}^{-1}$. Criteria for determining which estimator to use have been given by, for example, Ryzhkov et al. (2005); these are likely to be also applicable for the climate considered here.

\section{Summary}

The climate at high latitudes gives rise to unique challenges in radar remote sensing of rainfall, especially for space-based radars. The prevalence of light rain sets high demands on the sensitivity required from radars to observe the full range of rain rate. The small drops and the highly variable width of the drop size distributions complicate raindrop sizing using polarimetric and dualfrequency methods, causing a deterioration of the ability of these techniques to constrain the drop size.

In this study, we have compiled the results of of JossWaldvogel disdrometer observations in Järvenpää, Finland, taken over five years. The measured drop size spectra have been analyzed for the DSD parameters and have been combined with radar parameters that were computed from the spectra. The marginal and joint distributions of DSD parameters presented in this study describe the underlying microphysics that affects radar observations,
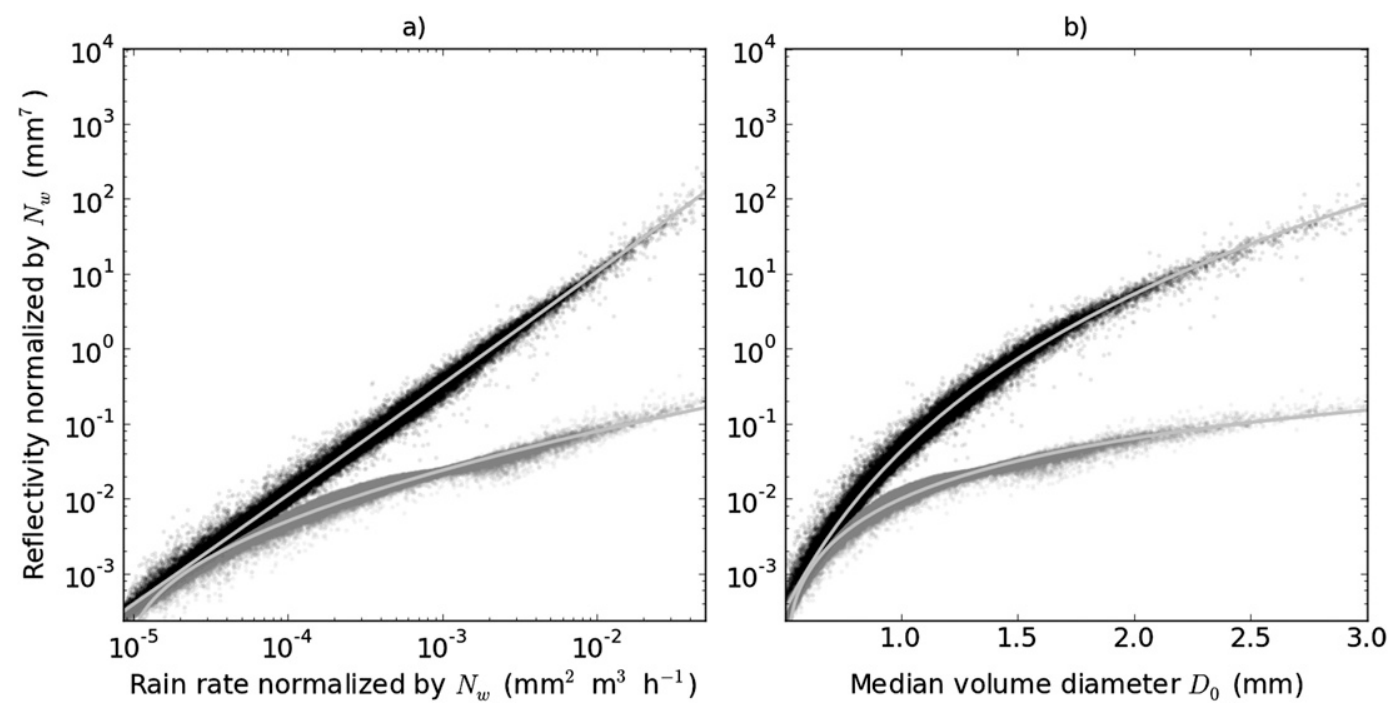

FIG. 15. Normalized relations of $z_{h}$ and the DSD parameters, with least squares fits using Eqs. (13) and (14), showing (a) the relation of $R / N_{w}$ and $z_{h} / N_{w}$ and (b) the relation of $D_{0}$ and $z_{h} / N_{w}$. Here, the black dots represent $\mathrm{C}$ band and the gray dots are for $\mathrm{W}$ band. 


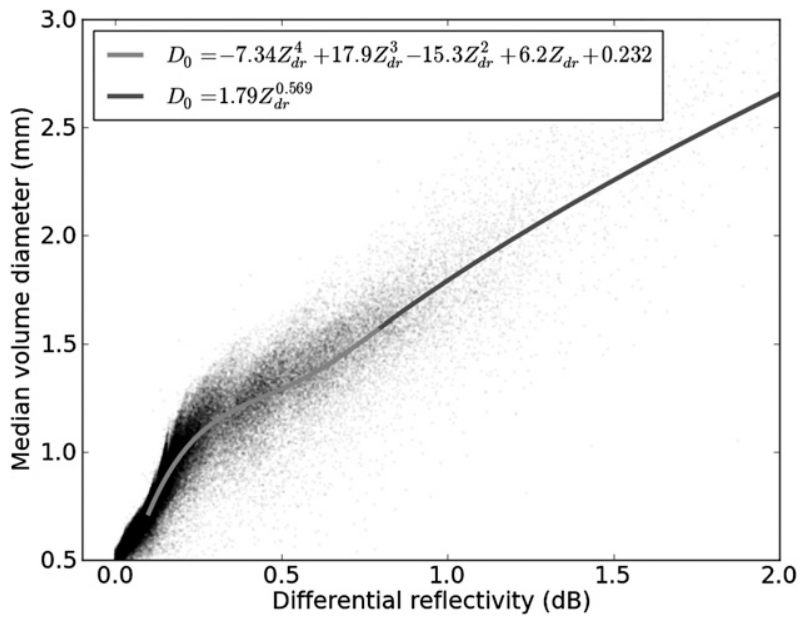

FIG. 16. A scatterplot of $Z_{\mathrm{dr}}$ and $D_{0}$ in the dataset. The line denotes a piecewise fit to the data.

and the statistics given for the computed radar parameters quantify the practical consequences for the ability to remotely observe rainfall in the studied climate. These two parts are connected to find the optimal retrieval algorithms implied by the dataset.

It is acknowledged here that the approach is somewhat idealized: determining the DSD from the drop counts depends on the assumption of known drop fall velocity as a function of size, and additionally the computation of radar parameters relies on assumptions about the raindrop shape and canting angle. Nevertheless, we can assume that, as long as these assumptions are not strongly biased, the random errors are averaged out in a large dataset. In addition, the random error and possible bias of radar systems are not included in the presented climatological summary but are present in real data.

For a long-term probability distribution of drop size, it was shown that the commonly used assumption of exponential size distribution holds at least down to the detection limit of the JWD at $0.32 \mathrm{~mm}$ (Fig. 2). In contrast, for the 60-s distributions (which are more representative of the local rain properties for radar purposes), the DSD properties in this climate reveal a few interesting differences from what was described in previously published studies. The small drop size and low average rain rate, which one can expect given the low amount of available radiative energy, were quantitatively demonstrated in Figs. 3-7. The DSDs were found to be narrow, corresponding typically to gamma distributions with $\mu \approx 4-9$, depending on the integration time, and commonly as high as $\mu>20$ for the 60 -s DSDs (Fig. 13). The drop concentration and diameter also behave statistically differently from what is observed in lower-latitude climates (Fig. 14). An interesting development would be to examine the connection between the variability of the DSD

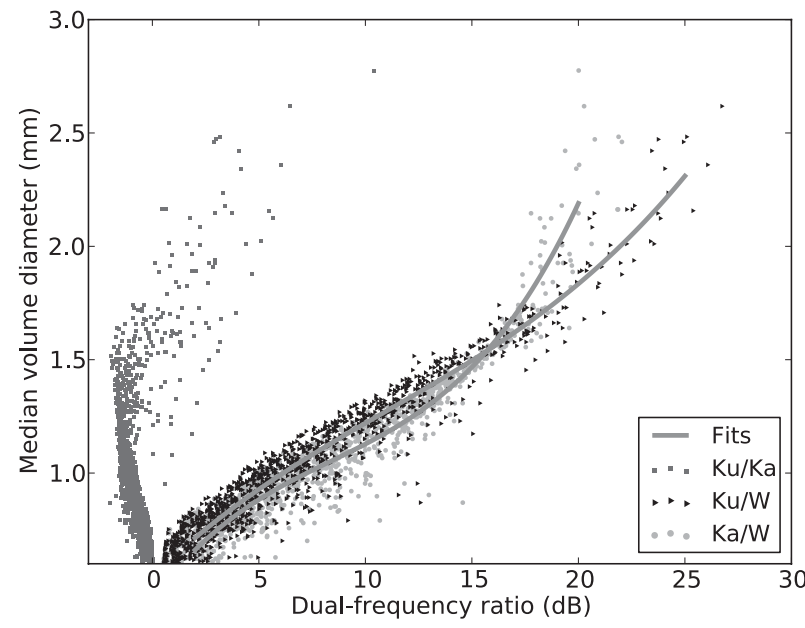

FIG. 17. A scatterplot of DFR and $D_{0}$ in the dataset. The lines denote polynomial fits of $D_{0}$ as a function of the $\mathrm{K}_{\mathrm{a}} / \mathrm{W}$-band and $\mathrm{K}_{\mathrm{u}} / \mathrm{W}$-band DFRs.

parameters and that of the local environmental factors, such as the diurnal cycle, time of year, and melting-layer height. A simple correlation analysis was performed, but the results were inconclusive, and thus the topic requires more detailed analysis in a later study.

The resulting distributions of important radar observables demonstrate the effects of the above-mentioned differences. We show that in high latitudes there are relatively strict requirements on the minimum detectable radar reflectivity $Z$ that is needed to attain a complete picture of rainfall. The rarity of heavy rain also diminishes the ability of the specific differential phase $K_{\mathrm{dp}}$ to improve the radar retrievals, except in the (obviously important) extreme events. The small drop size, and therefore the high raindrop sphericity, also increase the difficulty of constraining the retrievals with the oblateness-based measure of differential reflectivity $Z_{\mathrm{dr}}$. The differences also imply that optimal polarimetric retrieval coefficients should be determined using data from the local climate. Nevertheless, the rainfall detection rate of current polarimetric ground radars is at least as high as that of foreseeable spaceborne weather radars (and much higher in the case of GPM), thus providing a reliable data source for ground validation.

The combined effect of the small drops, and a coincidental resonance effect in the diameter range in which most of the drops are found, cause the DFR of $\mathrm{K}_{\mathrm{u}^{-}}$and $\mathrm{K}_{\mathrm{a}}$-band reflectivity to be below unity for a majority of the time, complicating retrievals. For DFR retrievals utilizing the $\mathrm{W}$ band the situation appears to be more promising, and a dual-frequency setup can help to constrain the DSD and thus to improve retrievals relative to a single frequency for the majority of the time. In combination with this result, the high sensitivity of W-band radar and the 
smaller (though still significant) average attenuation than is found in the tropics and the midlatitudes strengthen the case for measuring precipitation at high latitudes using dual-frequency radars with the $\mathrm{K}_{\mathrm{u}}$ or $\mathrm{K}_{\mathrm{a}}$ band for the lower frequency and the $\mathrm{W}$ band for the higher frequency.

Acknowledgments. This work was supported by the Academy of Finland GPM Grants 128255 and 128328. Walter A. Petersen acknowledges funding from both the NASA PMM Science Program (Dr. R. Kakar) and the NASA GPM Mission (Drs. A. Hou and M. Schwaller). Jussi Leinonen thanks Dr. V. N. Bringi for valuable discussions about the analysis.

\section{REFERENCES}

Barthazy, E., S. Göke, R. Schefold, and D. Högl, 2004: An optical array instrument for shape and fall velocity measurements of hydrometeors. J. Atmos. Oceanic Technol., 21, 1400-1416.

Brandes, E. A., G. Zhang, and J. Vivekanandan, 2002: Experiments in rainfall estimation with a polarimetric radar in a subtropical environment. J. Appl. Meteor., 41, 674-685.

,-- , and,- 2004 : Drop size distribution retrieval with polarimetric radar: Model and application. J. Appl. Meteor., 43, 461-475.

Bringi, V. N., and V. Chandrasekar, 2001: Polarimetric Doppler Weather Radar: Principles and Applications. Cambridge University Press, $636 \mathrm{pp}$.

—_, G.-J. Huang, V. Chandrasekar, and E. Gorgucci, 2002: A methodology for estimating the parameters of a gamma raindrop size distribution model from polarimetric radar data: Application to a squall-line event from the TRMM/Brazil campaign. J. Atmos. Oceanic Technol., 19, 633-645.

—, V. Chandrasekar, J. Hubbert, E. Gorgucci, W. L. Randeu, and M. Schoenhuber, 2003: Raindrop size distribution in different climatic regimes from disdrometer and dual-polarized radar analysis. J. Atmos. Sci., 60, 354-365.

- M. Thurai, and D. A. Brunkow, 2008: Measurements and inferences of raindrop canting angles. Electron. Lett., 44, $1425-1426$.

Campos, E., and I. Zawadzki, 2000: Instrumental uncertainties in $Z-R$ relations. J. Appl. Meteor., 39, 1088-1102.

Chandrasekar, V., and V. N. Bringi, 1987: Simulation of radar reflectivity and surface measurements of rainfall. J. Atmos. Oceanic Technol., 4, 464-478.

—, A. Hou, E. Smith, V. Bringi, S. Rutledge, E. Gorgucci, W. Petersen, and G. Skofronick-Jackson, 2008: Potential role of dual-polarization radar in the validation of satellite precipitation measurements. Bull. Amer. Meteor. Soc., 89, 1127-1145.

Gorgucci, E., V. Chandrasekar, V. N. Bringi, and G. Scarchilli, 2002: Estimation of raindrop size distribution parameters from polarimetric radar measurements. J. Atmos. Sci., 59, 2373-2384.

Hou, A. Y., G. Skofronick-Jackson, C. D. Kummerow, and J. M. Shepherd, 2008: Global precipitation measurement. Precipitation: Advances in Measurement, Estimation, and Prediction, S. Michaelides, Ed., Springer, 131-170.

Illingworth, A., and T. Blackman, 2002: The need to represent raindrop size spectra as normalized gamma distributions for the interpretation of polarization radar observations. J. Appl. Meteor., 41, 286-297.
Joss, J., and A. Waldvogel, 1967: A raindrop spectrograph with automatic analysis. Pure Appl. Geophys., 68, 240-246.

_, and 1969: Raindrop size distribution and sampling size errors. J. Atmos. Sci., 26, 566-569.

Kedem, B., and L. Chiu, 1987: On the lognormality of rain rate. Proc. Natl. Acad. Sci. USA, 84, 901-905.

Kidd, C., and P. Joe, 2007: Importance, identification and measurement of light precipitation at mid- to high-latitudes. Proc. Joint EUMETSAT Meteorological Satellite Conf. and 15th Satellite Meteorology and Oceanography Conf., Amsterdam, Netherlands, EUMETSAT and Amer. Meteor. Soc., 6 pp. [Available online at http://www.eumetsat.int/home/Main/ AboutEUMETSAT/Publications/ConferenceandWorkshop Proceedings/2007/groups/cps/documents/document/pdf_conf _p50_s8_04_kidd_p.pdf.]

Kuo, K.-S., E. A. Smith, Z. Haddad, E. Im, T. Iguchi, and A. Mugnai, 2004: Mathematical-physical framework for retrieval of rain DSD properties from dual-frequency $\mathrm{Ku}-\mathrm{Ka}$ band satellite radar. J. Atmos. Sci., 61, 2349-2369.

Mardiana, R., T. Iguchi, and N. Takahashi, 2004: A dual-frequency rain profiling method without the use of a surface reference technique. IEEE Trans. Geosci. Remote Sens., 42, 22142225.

Marshall, J. S., and W. M. Palmer, 1948: The distribution of raindrops with size. J. Meteor., 5, 165-166.

—, R. C. Langille, and W. M. Palmer, 1947: Measurement of rainfall by radar. J. Meteor., 4, 186-192.

Marzuki, M., W. Randeu, M. Schönhuber, V. Bringi, T. Kozu, and T. Shimomai, 2010: Raindrop size distribution parameters of distrometer data with different bin sizes. IEEE Trans. Geosci. Remote Sens., 48, 3075-3080.

Matrosov, S. Y., A. J. Heymsfield, and Z. Wang, 2005: Dual-frequency radar ratio of nonspherical atmospheric hydrometeors. Geophys. Res. Lett., 32, L13816, doi:10.1029/2005GL023210.

Meneghini, R., and L. Liao, 2007: On the equivalence of dualwavelength and dual-polarization equations for estimation of the raindrop size distribution. J. Atmos. Oceanic Technol., 24, 806-820.

— rain estimation methods from space using dual-wavelength radar measurements at near-nadir incidence over ocean. J. Atmos. Oceanic Technol., 9, 364-382.

Mishchenko, M., 2000: Calculation of the amplitude matrix for a nonspherical particle in a fixed orientation. Appl. Opt., 39, 1026-1031.

Moisseev, D. N., and V. Chandrasekar, 2007: Examination of the $\mu-\lambda$ relation suggested for drop size distribution parameters. J. Atmos. Oceanic Technol., 24, 847-855.

Ray, P. S., 1972: Broadband complex refractive indices of ice and water. Appl. Opt., 11, 1836-1844.

Ryzhkov, A. V., S. E. Giangrande, and T. J. Schuur, 2005: Rainfall estimation with a polarimetric prototype of WSR-88D. J. Appl. Meteor., 44, 502-515.

Sachidananda, M., and D. Zrnic, 1986: Differential propagation phase shift and rainfall rate estimation. Radio Sci., 21, 235-247.

Satoh, S., and Coauthors, 2004: Development of spaceborne dualfrequency precipitation radar for the Global Precipitation Measurement. Proc. 24th Int. Symp. on Space Technology and Science, Miyazaki City, Japan, ISTS, 6 pp. [Available online at http://okinawa.nict.go.jp/satoh/gpm/ISTS2004-n-06_Satoh.pdf.]

Sekhon, R. S., and R. C. Srivastava, 1971: Doppler radar observations of drop-size distributions in a thunderstorm. J. Atmos. Sci., 28, 983-994. 
Seliga, T. A., and V. N. Bringi, 1976: Potential use of radar differential reflectivity measurements at orthogonal polarizations for measuring precipitation. J. Appl. Meteor., 15, 69-76.

_, and _ 1978: Differential reflectivity and differential phase shift: Applications in radar meteorology. Radio Sci., 13, 271275.

Sheppard, B. E., and P. I. Joe, 1994: Comparison of raindrop size distribution measurements by a Joss-Waldvogel disdrometer, a PMS 2DG spectrometer, and a POSS Doppler radar. J. Atmos. Oceanic Technol., 11, 874-887.

Silverman, B. W., 1986: Density Estimation for Statistics and Data Analysis. Chapman and Hall/CRC, 175 pp.

Smith, P., and D. Kliche, 2005: The bias in moment estimators for parameters of drop size distribution functions: Sampling from exponential distributions. J. Appl. Meteor., 44, 1195-1205.

Stephens, G. L., and Coauthors, 2008: CloudSat mission: Performance and early science after the first year of operation. J. Geophys. Res., 113, D00A18, doi:10.1029/2008JD009982.
Testud, J., S. Oury, R. Black, P. Amayenc, and X. Dou, 2001: The concept of "normalized" distribution to describe raindrop spectra: A tool for cloud physics and cloud remote sensing. J. Appl. Meteor., 40, 1118-1140.

Thurai, M., G. J. Huang, V. N. Bringi, W. L. Randeu, and M. Schönhuber, 2007: Drop shapes, model comparisons, and calculations of polarimetric radar parameters in rain. J. Atmos. Oceanic Technol., 24, 1019-1032.

Tokay, A., D. B. Wolff, K. R. Wolff, and P. Bashor, 2003: Rain gauge and disdrometer measurements during the Keys Area Microphysics Project (KAMP). J. Atmos. Oceanic Technol., 20, 1460-1477.

_ P. G. Bashor, and K. R. Wolff, 2005: Error characteristics of rainfall measurements by collocated Joss-Waldvogel disdrometers. J. Atmos. Oceanic Technol., 22, 513-527.

Willis, P. T., 1984: Functional fits to some observed drop size distributions and parameterization of rain. J. Atmos. Sci., 41, $1648-1661$. 